segment whieh is not abruptly distinguished from the eighth a in the speries type,

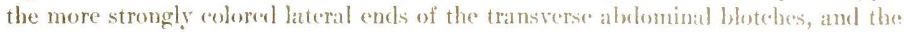
slightly larger size, the males being fully 2 mm., long, while fulcofosciatum is recorilew] as but $1.6 \mathrm{~mm}$. in lengeth (mate).

\title{
THE IIEMIITERA OF A.ATIT'A.
}

Notes on danarean llemptera: A Report on a collection of Hemiptera made on the Island of Jamaiea in the spring of 1906. 13y E. I'. Van Buze (Bull. Buttales

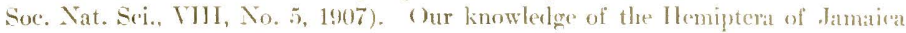
is greatly increased by this vahuable paper, in which are recordecl 236 with motes on distribution, ete. Of the above number $\$ .5$ were new to scienoe, the anthor describing about 54 speeies while the remander belonging to the family Capsiclat were feseriberl by Dr. O. M. Reuter in the Of. Finsk Vet-sone. Forbandl., XLIX, No, 5, Im, The author is to be congratulated on doing such a splendid month's work under adverse climatic ronditions. It elearly shows the value of sporialization. The locality Rivington, N. J., on pages 24 and (i9 shoukl real 'Thivertom."

$$
\text { C. II. J. }
$$

The four-color process plate which appeared in the octoler number was mate by the Sparrell Print of Boston. The Editors mish to make acknowledgment of their indebtedness to that establishment for friendly assistanre in the lesign of the plate, and scrupulous care in its produetion.

ERRATA. - Readers of Psrche are requested to make corrections als following in the articles by $2 \mathrm{r}$. A. A. Girault as printed in the current volume: Hosts of Inseet Parasites.

XIV, $190 \overline{7}, p .30$, th line from bottom, Trissoleus read Trissolens. p. 37, 15th line from bottom, Townsend reast Townend. last line, Chales reasl Charles.

p. 3S, sth line from bottom, Drew real Dru.

p. 39,7 th line

Catalogs read ('atalogus.

Colorado Potato Bcetle.

p. 47, 3rd paragraph, cruciform real crueiform.

p. 52, line 4 , is real its. 

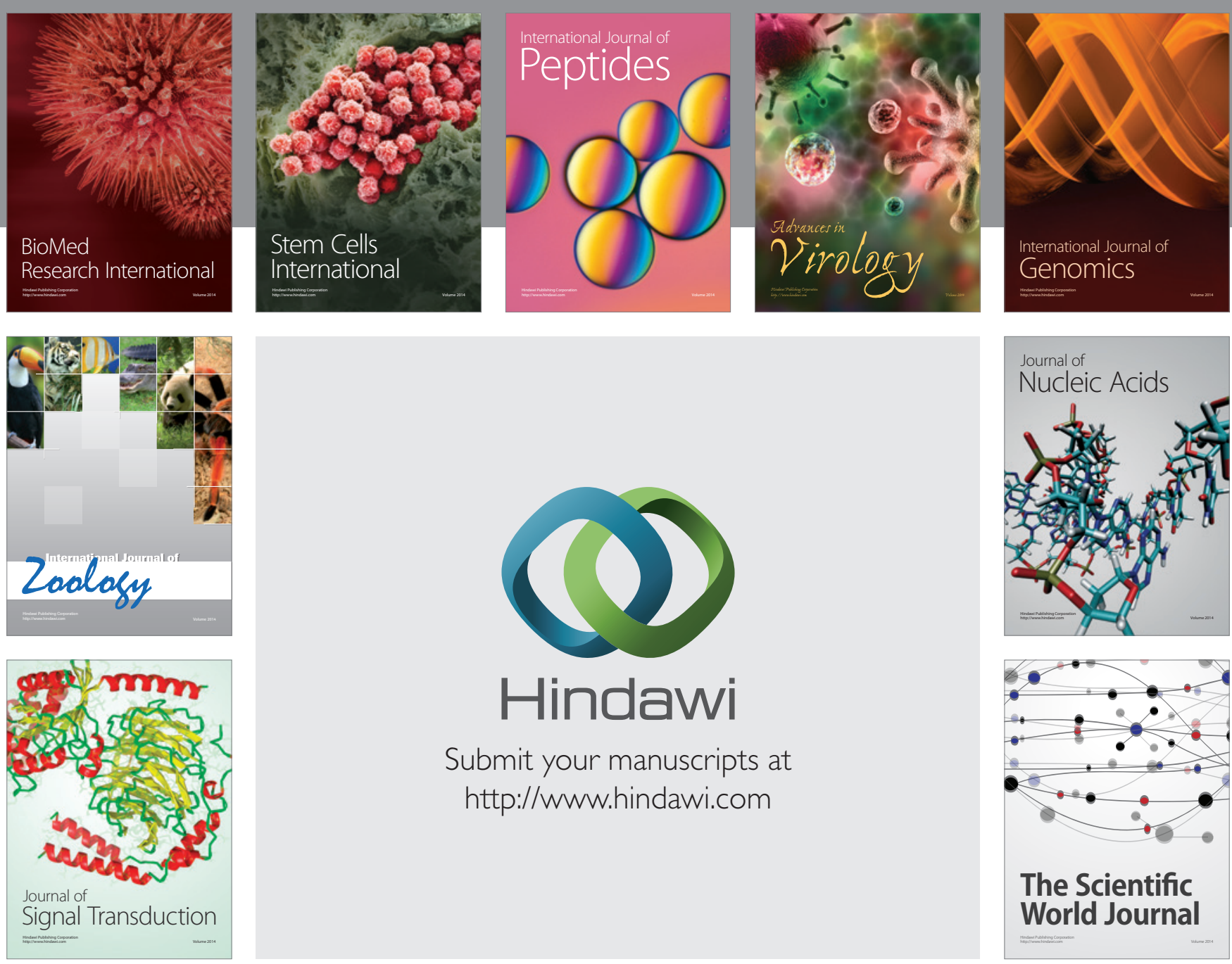

Submit your manuscripts at

http://www.hindawi.com
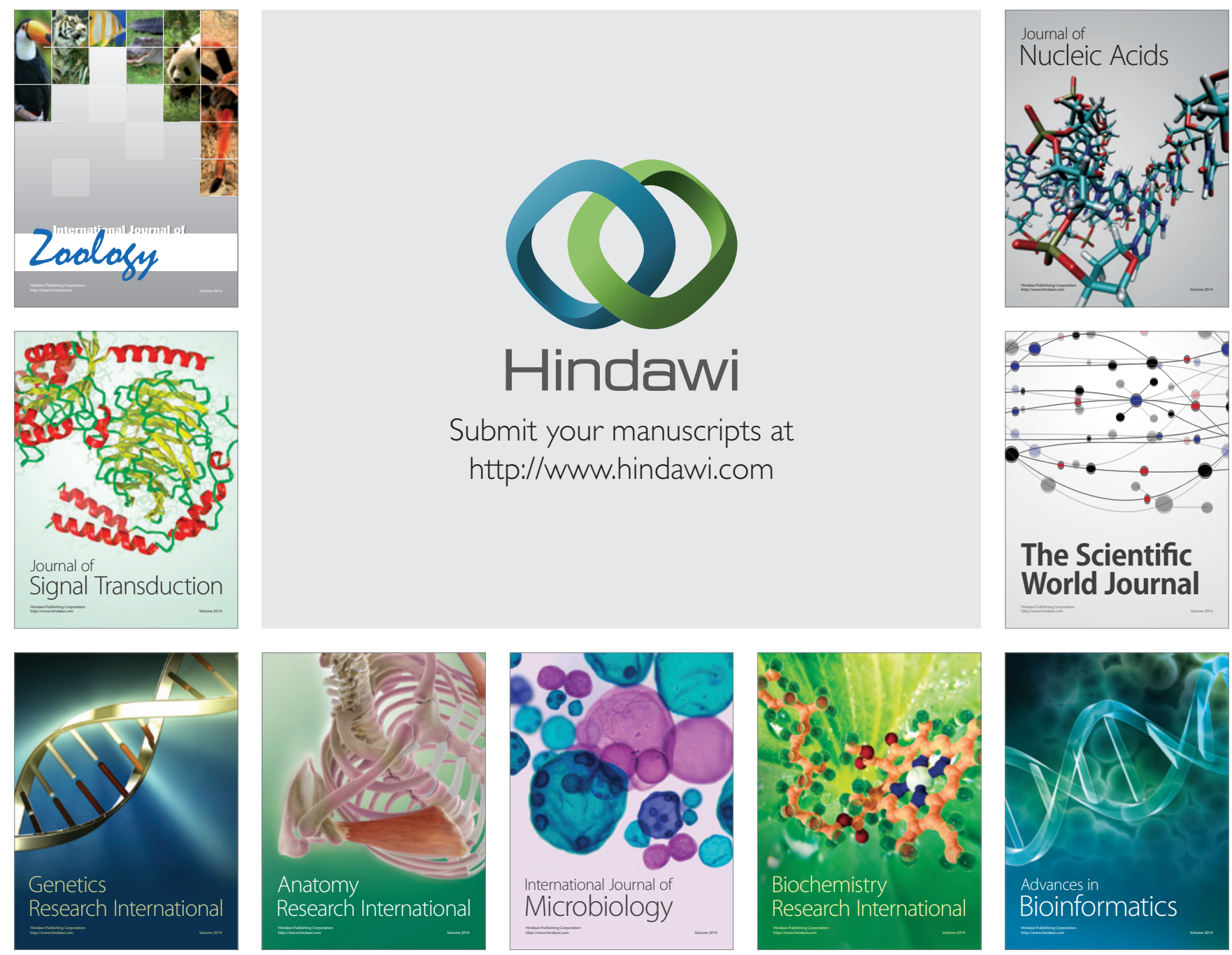

The Scientific World Journal
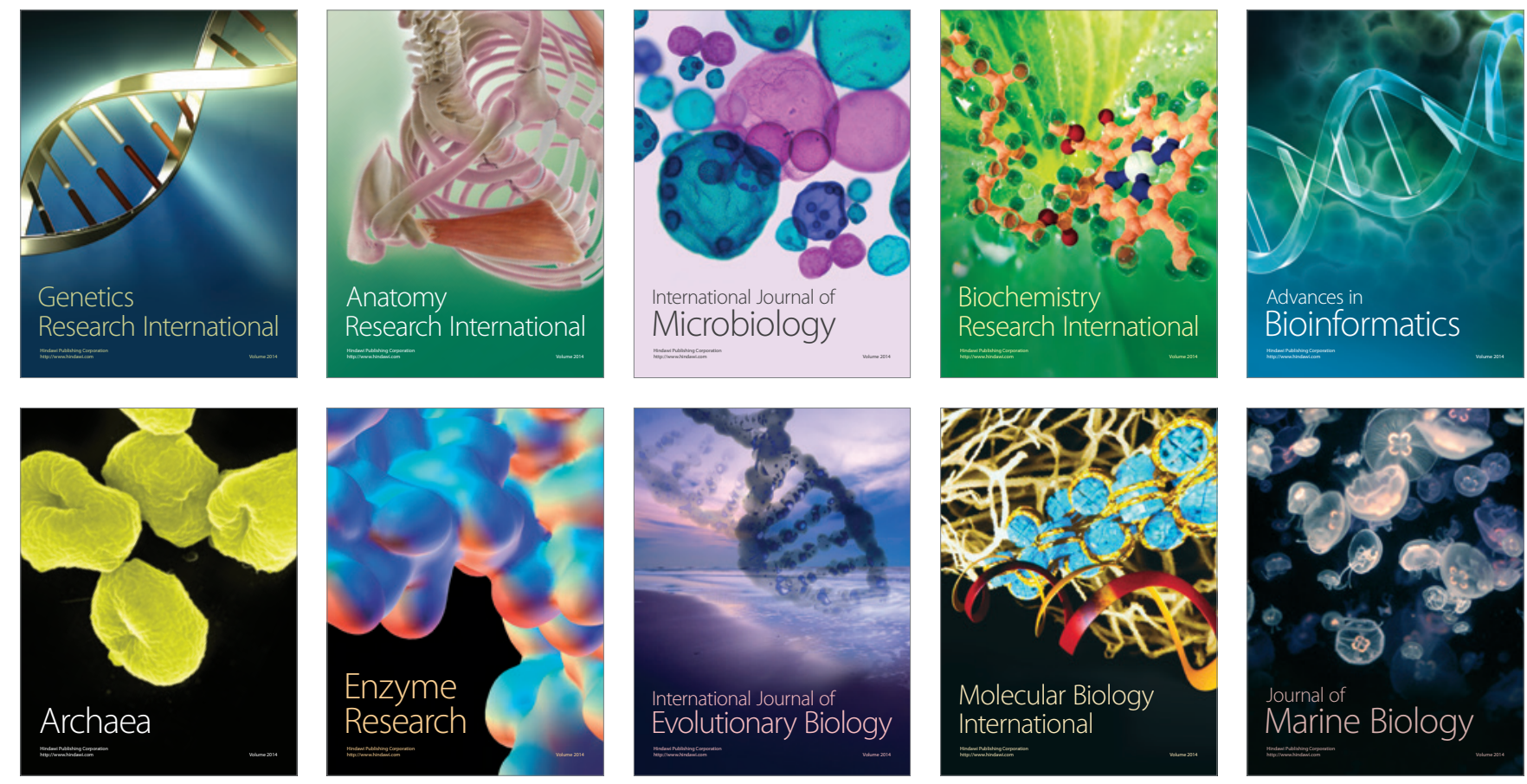